\title{
Mechanistic Insight into the Uptake and Fate of Persistent Organic Pollutants in Sea Ice
}

\author{
Jack Garnett, ${ }^{\dagger}$ Crispin Halsall, ${ }^{*}{ }^{\dagger}$ Max Thomas, ${ }^{\ddagger}$ James France, ${ }^{\ddagger}, \S, \|$ Jan Kaiser, ${ }^{\ddagger}$ Carola Graf, ${ }^{\dagger}$ \\ Amber Leeson, ${ }^{\dagger}$ and Peter $\mathrm{Wynn}^{\dagger}$ \\ ${ }^{\dagger}$ Lancaster Environment Centre, Lancaster University, Lancaster, LA1 4YQ U.K. \\ ${ }^{\ddagger}$ Centre for Ocean and Atmospheric Sciences, School of Environmental Sciences, University of East Anglia, Norwich Research Park, \\ Norwich, NR4 7TJ, U.K. \\ ${ }^{\S}$ British Antarctic Survey, High Cross, Madingley Road, Cambridge, CB3 0ET, U.K. \\ "Department of Earth Sciences, Royal Holloway, University of London, Egham Hill, Egham TW20 0EX, U.K.
}

Supporting Information

\begin{abstract}
The fate of persistent organic pollutants in sea ice is a poorly researched area and yet ice serves as an important habitat for organisms at the base of the marine foodweb. This study presents laboratory-controlled experiments to investigate the mechanisms governing the fate of organic contaminants in sea ice grown from artificial seawater. Sea ice formation was shown to result in the entrainment of chemicals from seawater, and concentration profiles in bulk ice generally showed the highest levels in both the upper (iceatmosphere interface) and lower (ice-ocean interface) ice layers, suggesting their incorporation and distribution is influenced by brine advection. Results from a 1-D sea ice brine dynamics model supported this, but also indicated that

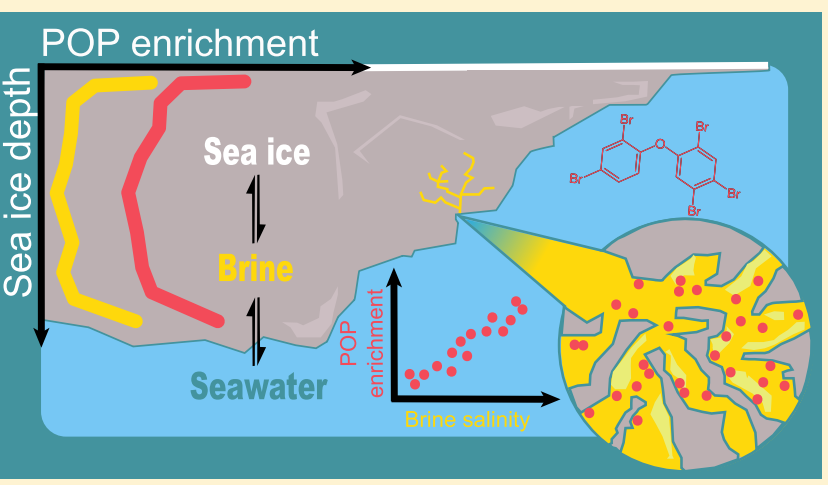
other processes may be needed to accurately model low-polarity compounds in sea ice. This was reinforced by results from a melt experiment, which not only showed chemicals were more enriched in saltier brine, but also revealed that chemicals are released from sea ice at variable rates. We use our results to demonstrate the importance of processes related to the occurrence and movement of brine for controlling chemical fate in sea ice which provides a pathway for exposure to ice-associated biota at the base of the pelagic food web.
\end{abstract}

\section{INTRODUCTION}

Persistent organic pollutants (POPs) comprise a large group of mainly synthetic, toxic chemicals that have long environmental half-lives and are subject to long-range transport by global atmospheric and oceanic circulation currents. ${ }^{1}$ As such, these chemicals are present in the marine environment of polar regions and have been shown to bioaccumulate and biomagnify in Arctic food webs ${ }^{2,3}$ The role of snow and sea ice in the fate and transfer of both older "legacy" and contemporary "emerging" chemicals to biological systems has not been well studied despite their occurrence in Arctic seawater. There are now a number of observational studies that have reported relatively high POP concentrations in the remote sea ice snowpack ${ }^{4-6}$ and their presence in sea ice itself. $^{7-10}$

A warming climate is resulting in substantial changes to the volume and properties of sea ice. ${ }^{11}$ There is a strong declining trend in the areal extent of Arctic sea ice cover, which currently ranges between 4 and 16 million $\mathrm{km}^{2}$ over the annual seasonal cycle. ${ }^{12}$ Furthermore, the nature of sea ice is also changing, with the Arctic Ocean now dominated by first-year sea ice
(FYI). ${ }^{13}$ As sea ice forms, most of the salts present in the freezing seawater are rejected into the underlying ocean, leaving only a small amount entrapped within a network of highly saline brine pockets. As ice continues to grow, more salts are expelled and seasonal meltwater at the surface often "flushes" the sea ice, reducing its bulk salinity further. Multiyear sea ice (MYI), therefore, has a lower bulk salinity and a lower salt flux to the ocean during melt ${ }^{14}$. Conversely, young ice contains more brine per unit volume, and this appears to influence the behavior and fate of organic micropollutants present in the sea ice system. ${ }^{8}$ Importantly, many organisms situated at the base of the pelagic food web are abundant in sea ice and inhabit the network of brine inclusions. As the Arctic environment is rapidly changing, there is a rising motivation to understand the biogeochemical cycling of these toxic chemicals in sea ice.

Received: February 19, 2019

Revised: May 15, 2019

Accepted: May 23, 2019

Published: May 23, 2019 
While the presence of POPs such as polychlorinated biphenyls (PCBs) has been established in sea ice ${ }^{7}$ most of the recent knowledge on chemical behavior in sea ice and interactions with seawater and the overlying snowpack has been established through the field observations of Pucko et al., $5,6,8,9,15,16$ who examined the $\alpha$ - and $\gamma$-isomers of hexachlorocyclohexane $(\mathrm{HCH})$ in FYI in the Amundsen Gulf of the Canadian Arctic. The key findings from these studies showed sea ice to have some of the highest concentrations of $\mathrm{HCHs}$ measured anywhere in the Arctic. The majority of the $\mathrm{HCHs}$ were present in brine, and brine advection influenced the transfer of $\mathrm{HCHs}$ between the sea ice, overlying snowpack, and underlying seawater.

The aim of this study was to better understand the basic mechanisms governing the uptake and release of organic pollutants in growing and melting sea ice, respectively. We hypothesize that chemical uptake and distribution is strongly influenced by the formation of brine during sea ice growth and melt. To test this, we performed sea ice growth experiments under controlled laboratory conditions where an artificial "ocean" was spiked with several persistent organic pollutants. To assess the role of brine in determining their fate, we measured vertical profiles of pollutant concentrations through bulk sea ice samples and made comparisons to predictions from a sea ice brine dynamics model during sea ice formation. We also conducted an experiment to extract brine and assess its composition to examine how organic chemicals are released from sea ice during melt.

\section{MATERIALS AND METHODS}

2.1. Experimental Facility and Conditions. The study was conducted in the Roland von Glasow Air-Sea-Ice Chamber (RvG-ASIC) at the University of East Anglia, UK. In essence, the facility consists of a glass-walled tank (approximately 3.5 $\mathrm{m}^{3}$; height: $1.2 \mathrm{~m}$; width $1.2 \mathrm{~m}$; length $2.5 \mathrm{~m}$ ) located inside an enclosed chamber that can be chilled to $-55{ }^{\circ} \mathrm{C}$ (see https:// www.uea.ac.uk/environmental-sciences/sea-ice-chamber). The tank was filled with artificial seawater (deionized water with $\mathrm{NaCl}-($ AksoNobel Sanal-P; purity $>99.5 \%)$ ). A submerged pump (flow rate: $1000 \mathrm{~L} \mathrm{~h}^{-1}$ ) was used to mix the seawater (SW; we refer to it as seawater even though it only contains $\mathrm{NaCl}$ ). The tank was equipped with an in situ conductivitytemperature sensor (SeaStar DST CTD) along with a series of automated in situ thermistors spanning the depth of the ice profile to measure the ice temperature throughout the experimental periods. Table 1 presents an overview of the experimental conditions for two freeze periods ( 1 and 2). For the main experiment (Freeze-1), the air temperature of the chamber was chilled to $-35^{\circ} \mathrm{C}$ for 3 days resulting in rapid ice growth and the formation of an ice layer $17 \pm 1 \mathrm{~cm}$ in depth (uncertainty reflects ice thickness variations across the tank). The ice was subsequently sampled to establish the presence of chemicals in the ice and their distribution throughout the ice column. After the ice had completely melted, "Freeze-2" was undertaken with the air temperature set to $-18{ }^{\circ} \mathrm{C}$, but for a longer duration ( 7 days), resulting in slower ice growth but with a thicker final ice layer $26 \pm 1 \mathrm{~cm}$. The ice sampled during "Freeze-2" was also subject to an additional slow-melt experiment to assess chemical behavior during melt (see Section 2.4.).

An array of chemicals that have been previously observed in the Arctic marine system (see Table 2) and that cover a wide range of physical-chemical properties (SITable S1) were
Table 1. Experimental Conditions and Sea Ice Physical Properties for Two Freeze Experiments ${ }^{a}$

$\begin{array}{lll} & \text { Freeze }-1 & \text { Freeze }-2 \\ \text { initial } \mathrm{NaCl} \text { concentration }\left(\mathrm{g} \mathrm{L}^{-1}\right) & 35.4 \pm 0.1 & 35.4 \pm 0.1 \\ \text { air temperature during freezing phase }\left({ }^{\circ} \mathrm{C}\right) & -35 & -18 \\ \text { air temperature during melting phase }\left({ }^{\circ} \mathrm{C}\right) & 5 & 0 \\ \text { maximum sea ice depth }(\mathrm{cm}) & 17 \pm 1 & 26 \pm 1 \\ \text { freezing duration (days) } & 3 & 7 \\ \text { coldest recorded temperature in ice }\left({ }^{\circ} \mathrm{C}\right) & -13.8 & -11.3 \\ \text { maximum modeled brine salinity }\left(\mathrm{g} \mathrm{L}^{-1}\right) & 178.2^{b} & 154.8^{b} \\ \text { average ice growth rate }\left(\mathrm{cm} \mathrm{d}^{-1}\right) & 5.7 & 3.7 \\ \text { melting phase (days) } & 6 & 3\end{array}$

${ }^{a}$ Sea ice samples used to assess chemical release in the slow-melt experiment were taken from Freeze -2 (see Section 2.4). ${ }^{b}$ Derived using the recorded minimum temperature in the sea ice using Equation $S 1 .{ }^{17}$

Table 2. Chemical Mass ( \pm 1 SD) Apportionment for the Experimental Compartments on Days 1, 4, and 11 of Freeze $-1$

\begin{tabular}{|c|c|c|c|c|c|}
\hline \multirow{2}{*}{$\begin{array}{c}\begin{array}{c}\text { experimental } \\
\text { day }\end{array} \\
\text { compartment }\end{array}$} & \multirow{2}{*}{$\begin{array}{c}\begin{array}{c}\text { start } \\
(\text { day 1) }\end{array} \\
\text { seawater }\end{array}$} & \multicolumn{3}{|c|}{ middle (day 4) } & \multirow{2}{*}{$\begin{array}{c}\text { end } \\
\text { (day 11) }\end{array}$} \\
\hline & & seawater & bulk ice & $\begin{array}{c}\text { frost } \\
\text { flowers }\end{array}$ & \\
\hline $\begin{array}{l}\text { volume fraction } \\
\text { of } \\
\text { compartment }\end{array}$ & $100 \pm 1$ & $83 \pm 1$ & $17 \pm 1$ & $\ll 1$ & $100 \pm 1$ \\
\hline $\mathrm{NaCl}\left(\%_{\text {mass }}\right)$ & $100 \pm 1$ & $93 \pm 1$ & $7 \pm 1$ & $\ll 1$ & $100 \pm 1$ \\
\hline$\alpha-\mathrm{HCH}\left(\%_{\text {mass }}\right)$ & $100 \pm 15$ & $96 \pm 18$ & $4 \pm 1$ & $\ll 1$ & $97 \pm 14$ \\
\hline$\gamma-\mathrm{HCH}\left(\%_{\text {mass }}\right)$ & $100 \pm 22$ & $97 \pm 34$ & $3 \pm 1$ & $\ll 1$ & $83 \pm 2$ \\
\hline PCB-28 (\% $\left.\%_{\text {mass }}\right)$ & $100 \pm 18$ & $93 \pm 10$ & $7 \pm 1$ & $\ll 1$ & $116 \pm 17$ \\
\hline PCB-52 (\% $\left.\%_{\text {mass }}\right)$ & $100 \pm 12$ & $96 \pm 14$ & $4 \pm 1$ & $\ll 1$ & $108 \pm 11$ \\
\hline $\begin{array}{c}\text { chlorpyrifos } \\
\left(\%_{\text {mass }}\right)\end{array}$ & $100 \pm 29$ & $96 \pm 32$ & $4 \pm 1$ & $\ll 1$ & $156 \pm 42$ \\
\hline BDE-47 (\% $\left.\%_{\text {mass }}\right)$ & $100 \pm 16$ & $94 \pm 64$ & $6 \pm 2$ & $\ll 1$ & $114 \pm 32$ \\
\hline BDE-99 (\% $\left.\%_{\text {mass }}\right)$ & $100 \pm 17$ & $91 \pm 48$ & $9 \pm 3$ & $\ll 1$ & $80 \pm 5$ \\
\hline
\end{tabular}

spiked into the tank using a stock solution $(0.2-1.4 \mu \mathrm{M}$ in $1 \mathrm{~L}$ ethanol) to give concentrations between 0.1 and $0.4 \mathrm{nM}$ (SI Table S2). This was undertaken once the temperature of the seawater had cooled to $-1{ }^{\circ} \mathrm{C}$ to ensure minimal loss of chemicals by volatilisation. The chemical concentrations were up to 2 orders of magnitude below the estimated aqueous solubilities in seawater (see SI Table S1), but also up to 2 orders of magnitude greater than those typically observed in Arctic seawater. The freeze experiments conducted in the facility were performed in darkness to limit the growth of algae and reduce any photochemical loss of the compounds.

2.2. Sampling Procedures. Prior to the introduction of chemicals into the chilled seawater, a short period ( 2 days) of ice growth at $-35^{\circ} \mathrm{C}$ permitted samples of seawater (SW) $(0.2$ $\mathrm{L} ; n=3)$ and bulk ice (BI) $(3.5 \mathrm{~L} ; n=1)$ to be collected for the purpose of method blanks. After the ice had melted, the chemical stock spike solution was added and mixed under pumping. A seawater sample $(0.2 \mathrm{~L} ; n=1)$ was taken daily, and triplicate samples $(0.2 \mathrm{~L} ; n=3)$ were obtained on three key days of Freeze -1 (start: day 1 (before any ice formation); middle: day 4 (once maximum ice had formed); end: day 11 (after complete ice melt)) to assess analytical precision. Seawater was taken via a preinstalled silicone hose (i.d. $8 \mathrm{~mm}$ ) with an inlet set at $0.5 \mathrm{~m}$ above the base of the tank to avoid interference with any forming ice layer. Bulk ice samples $(n=$ 2) were taken once the ice had reached a suitable handling 
depth using techniques developed by Cottier et al., ${ }^{18}$ to limit brine loss and displacement during sampling. Following sampling, ice samples were immediately wrapped in precleaned polyethylene $(\mathrm{PE})$ sheets and transferred to a freezer $\left(-40^{\circ} \mathrm{C}\right)$ where they were stored prior to further processing. Bulk ice samples were subsequently sectioned into horizontal layers $(0.4-1.2 \mathrm{~L}$ each; $n=9)$ using a grease-free electric band saw in a cold room $\left(-25{ }^{\circ} \mathrm{C}\right)$, transferred to individual PE bags, and melted at room temperature. Frost flowers $(0.2 \mathrm{~L} ; n=1)$ present on the surface of the ice were carefully collected using a polyethylene spatula and stored in a freezer before melting for analysis.

2.3. Sample Processing and Analysis. Salinity was measured in melted sea ice samples, "slow-melt" aliquots, and melted frost flowers using a calibrated conductivity probe (Hach HQd40 logger with CDC401 probe) after $50 \mu \mathrm{L}$ of surrogate standard $\left(\left({ }^{13} \mathrm{C}\right) \mathrm{PCB}-28,\left({ }^{13} \mathrm{C}\right) \mathrm{PCB}-52,\left({ }^{13} \mathrm{C}\right) \mathrm{PCB}-\right.$ 180 at $60 \mathrm{pg} \mu \mathrm{L}^{-1}$ in ethanol) was added to each solution. Samples were then subject to solid phase extraction (SPE) using a 12-port vacuum manifold system. Briefly, SPE cartridges ( $30 \mathrm{mg}$ of $3 \mathrm{cc}$ OASIS HLB) were conditioned using $5 \mathrm{~mL}$ of methanol followed by $5 \mathrm{~mL}$ of chemical-free purified water (Milli- $Q_{i}>18 \mathrm{M} \Omega \mathrm{cm}$ ) and then loaded with sample at a rate of $1-2$ drops per second. Subsequently, the cartridges were centrifuged for $5 \mathrm{~min}$ at $2000 \mathrm{rpm}$ and later airdried for a further $40 \mathrm{~min}$ while fitted with an additional cartridge as a precaution against airborne contamination. Cartridges were then soaked with $3 \mathrm{~mL}$ of hexane:dichloromethane (1:1) for $5 \mathrm{~min}$ and eluted with a further $3 \mathrm{~mL}$ of this solvent mix. Each sample extract was then subject to a cleanup procedure involving elution through an alumina/silica column followed by gel permeation chromatography (GPC). Samples were then transferred to amber GC vials containing $50 \mu \mathrm{L}$ of recovery standard (IS) $\left(\left[{ }^{13} \mathrm{C}\right] \mathrm{PCB}-141\left[25 \mathrm{pg} \mu \mathrm{L}^{-1}\right]\right.$ and BDE-69 [75 pg $\left.\left.\mu \mathrm{L}^{-1}\right]\right)$ in $n$-dodecane was then added before being reduced under $\mathrm{N}_{2}$ to a final volume of $50 \mu \mathrm{L}$.

Analysis of extracts was performed using a Thermo GC-MS (Trace GC Ultra - DSQ) (Xcalibur software Version 1.4.x) operating in electron impact mode $(70 \mathrm{eV})$ and equipped with an Agilent CP-Sil 8 CB $50 \mathrm{~m} \times 0.25 \mathrm{~mm}$ capillary column with $0.12 \mu \mathrm{m}$ film thickness. A 10-point mixed calibration standard in $n$-dodecane was used for quantification $\left(10-450 \mathrm{pg} \mu \mathrm{L}^{-1}\right.$

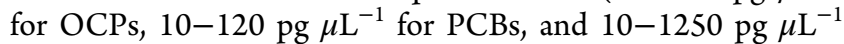
for PBDEs, respectively). Chemical concentrations presented in this study were corrected for recovery, but not blank corrected. Method detection limits (MDL) were calculated from method blanks $\left(\mathrm{MDL}=\bar{x}_{\text {method blank }} \pm 3 \cdot \mathrm{SD}\right.$ method blank $)$ (see SI Table S3).

2.4. Slow-Melt Experiment. Following Freeze-2, a separate experiment was conducted (outside of the glass tank but within the coldroom) to examine the release of chemicals from ice during thaw, and to determine how strongly associated each chemical was with brine. Sea ice cores $(n=$ 8 ) were sampled from across the ice slab using a precleaned titanium manual ice corer $(75 \mathrm{~mm}$ i.d.). These were individually split into top (T) and bottom (B) sections of approximately equal length, with each section placed into a separate precleaned $\mathrm{PE}$ bag, which were subsequently kept at 0 $\pm 1{ }^{\circ} \mathrm{C}$ to induce melt, as described by Pućko et al., 8 and others. ${ }^{19-22}$ Sequential meltwater (MW) fractions (0.1 to 1.2 $\mathrm{L} ; n=8$ ) were collected from the respective top and bottom sections and analyzed separately (SI Table S4).
2.5. Calculations and Data analysis. Enrichment factors (EF) were calculated using eq 1 to assess the accumulation of chemicals in a particular compartment, relative to seawater. The average chemical concentration of all seawater samples over the experimental period was used for the denominator for each chemical (SW; day 1 to day 11). The brine (BR) assessed in this study was operationally defined using the average of the first meltwater (MW) fraction from both the top and bottom ice sections $\left(\mathrm{MW}_{\mathrm{F} 1 \mathrm{~T}}\right.$ and $\left.\mathrm{MW}_{\mathrm{F} 1 \mathrm{~B}} ; n=2\right)$ and $\mathrm{FF}$ is a frost flower sample (taken in Freeze-1). Hence, EF values $>1$ and $<1$ indicate specific enrichment or depletion, relative to seawater, respectively.

$$
\mathrm{EF}=\frac{[\text { chemical }]_{\text {e.g.bulkice(BI);brine }(\mathrm{BR}) \text {; frostflower(FF);meltwater(MW); }}}{[\text { chemical }]_{\text {seawater }(\mathrm{SW})}}
$$

Sea ice depths were normalized to the total sea ice thickness in that experiment (i.e., in Freeze-1 and -2) to aid comparison between modeled and measured data. A mass-balance calculation was used to assess chemical loss from the system (e.g., volatilization and/or chamber-side sorption) and evaluate the fraction of chemical present in the various compartments, that is, seawater, bulk ice, and brine (at maximum ice depth). Average sea ice concentrations were used to calculate the mass fraction of chemical in the bulk ice, with respect to the total measured mass in the seawater at day 1 . The relative standard deviation (RSD) of triplicate seawater samples were used to calculate conservative estimates of the variability of some samples (e.g., frost flowers) (see SI Table S3). For more information on calculations and data analysis, refer to SI eqs S1-S5).

2.6. Brine Dynamics Model. A 1-dimensional sea ice growth and desalination model was used to predict brine dynamics in a forming sea-ice layer, using the gravity drainage parametrization presented by. ${ }^{17}$ The model is presented in detail in Thomas et al., ${ }^{23}$ where it is has been shown to have predictive capability for the dynamics of brine in sea ice. The brine dynamics parametrization has also been evaluated previously. ${ }^{17}$ The model was initialized by prescribing an initial seawater salinity, concentration of a dissolved solute in seawater (e.g., an organic chemical), sea ice thickness, and ocean mass. For this study, the initial salinity and chemical concentrations were taken from the measured values in the seawater at the beginning of the experiment (i.e., day 1 ). The model was run with $\pm 2 \mathrm{SD}$ of the initial starting conditions, based on the precision of the measurements of the chemical concentrations in the seawater. The initial sea ice thickness was set to $1 \mathrm{~cm}$, and the bulk sea ice salinity and chemical concentrations were set to initial ocean concentrations for all model sea ice layers. The model was forced using measured sea ice temperature profiles, and sea ice thicknesses calculated by extrapolating those profiles back to the measured seawater temperature. In this case, measurements were used instead of a thermodynamic model to minimize errors. Full details including the key equations governing brine salinity (derived using the ice temperature), and how the model simulates brine dynamics (gravity drainage) are presented in the SI.

\section{RESULTS AND DISCUSSION}

3.1. Quality Controls and Mass-Balance. Average recoveries of the surrogate standards were $42 \pm 17 \%$ and did not vary significantly between sample type (SI Table S3). 
Table 3. Enrichment Factors $\left( \pm 1\right.$ SD) for $\mathrm{NaCl}$ and Chemical Contaminants in the Different Sea Ice System Compartments ${ }^{a}$

\begin{tabular}{|c|c|c|c|c|c|c|c|c|c|c|}
\hline $\begin{array}{l}\text { Enrichment } \\
\text { Factor }\end{array}$ & $\begin{array}{c}\text { Bulk ice } \\
\text { depth(cm) }\end{array}$ & $\mathrm{NaCl}$ & $\mathrm{a}-\mathrm{HCH}$ & $\mathrm{Y}-\mathrm{HCH}$ & PCB-28 & PCB-52 & Chlorpyrifos & BDE-47 & BDE-99 & Reference \\
\hline $\mathrm{EF}_{\mathrm{BI}-\mathrm{SW}}$ & $17 \pm 1$ & $0.4 \pm<0.1$ & $0.1 \pm<0.1$ & $0.1 \pm 0.1$ & $0.2 \pm 0.1$ & $0.2 \pm<0.1$ & $0.2 \pm 0.1$ & $0.1 \pm 0.1$ & $0.4 \pm 0.2$ & Freeze -1 \\
\hline $\mathrm{EF}_{\mathrm{BI}-\mathrm{SW}}$ & $26 \pm 1$ & $0.3 \pm<0.1$ & $0.2 \pm 0.1$ & $0.3 \pm 0.2$ & $0.2 \pm 0.1$ & $0.1 \pm<0.1$ & $0.3 \pm 0.2$ & $0.2 \pm 0.1$ & $0.4 \pm 0.2$ & Freeze - 2 \\
\hline $\mathrm{EF}_{\mathrm{BI}-\mathrm{SW}}$ & 30 & 0.4 & 0.4 & 0.5 & \multicolumn{5}{|c|}{$\mathrm{n} / \mathrm{m}$} & 8 \\
\hline $\mathrm{EF}_{\mathrm{BI}-\mathrm{SW}}$ & 90 & 0.2 & 0.3 & 0.3 & \multicolumn{5}{|c|}{$\mathrm{n} / \mathrm{m}$} & 9 \\
\hline $\mathrm{EF}_{\mathrm{BI}-\mathrm{SW}}$ & 5 & 0.3 & 0.3 & 0.4 & \multicolumn{5}{|c|}{$\mathrm{n} / \mathrm{m}$} & 9 \\
\hline $\mathrm{EF}_{\mathrm{BR}-\mathrm{SW}}$ & $26 \pm 1$ & $1.4 \pm<0.1$ & $0.6 \pm 0.2$ & $1.0 \pm 0.8$ & $1.3 \pm 0.5$ & $1.2 \pm 0.3$ & $1.2 \pm 0.7$ & $0.7 \pm 0.5$ & $0.9 \pm 0.6$ & Freeze - 2 \\
\hline $\mathrm{EF}_{\mathrm{BR}-\mathrm{SW}}$ & 90 & 4.4 & 3.9 & 4 & \multicolumn{5}{|c|}{$\mathrm{n} / \mathrm{m}$} & 8 \\
\hline$E_{\text {FF-SW }}$ & $\mathrm{n} / \mathrm{a}$ & $2.3 \pm<0.1$ & $0.2 \pm 0.1$ & $0.2 \pm 0.2$ & $0.2 \pm 0.1$ & $0.4 \pm 0.1$ & $0.3 \pm 0.2$ & $6.6 \pm 4.4$ & $24 \pm 15$ & Freeze - 1 \\
\hline EF FF-sW $_{\text {F }}$ & $\mathrm{n} / \mathrm{a}$ & $<2.0$ & 0.7 & 2.1 & \multicolumn{5}{|c|}{$0.0-38.9^{\Delta}$} & 10 \\
\hline$E F_{F F-L 1}$ & $n / a$ & $5.0 \pm<0.1$ & $1.5 \pm 0.5$ & $2.0 \pm 1.5$ & $2.5 \pm 0.9$ & $3.0 \pm 0.7$ & $2.4 \pm 1.4$ & $30 \pm 20$ & $50 \pm 31$ & Freeze - 1 \\
\hline $\mathrm{EF}_{\mathrm{FF}-\mathrm{L} 1}$ & $\mathrm{n} / \mathrm{a}$ & $<0.7$ & & & & $1.7-68.0$ & & & & 10 \\
\hline
\end{tabular}

${ }^{a} \mathrm{BI}=$ bulk ice; $\mathrm{BR}=$ brine; $\mathrm{SW}=$ seawater; $\mathrm{FF}=$ frost flower; $\mathrm{L} 1=$ uppermost sea ice layer sampled. $\mathrm{n} / \mathrm{a}=$ not applicable; $\mathrm{n} / \mathrm{m}=\mathrm{not}$ measured; $\Delta$ $=$ different organic chemical used other than that analyzed in this study. See SI Table S5 for values that were used in this literature analysis.

Some blanks contained low levels of several target analytes (e.g., $\alpha$-HCH, $\gamma$-HCH, PCB-28, PCB-52) thereby increasing the method detection limits (MDLs) for these compounds. The relative standard deviation (RSD) of triplicate seawater analyses demonstrated precisions of $8-40 \%$ between all test compounds (see SI Table S3). Table 2 shows the relative distribution of chemicals in the various compartments of the experimental system on selected days. By day 11 , all of the ice had melted and a comparison of the relative mass in the seawater on the initial (day 1) and final (day 11) days of the experiments showed that there was no significant difference ( $p$ $>0.05$; student $t$ test) for any of the chemicals, indicating negligible losses during the experimental period. Hence, all of the chemicals in the system can be accounted for and are not subject to an artifact of the experimental setup.

Under natural conditions, the transfer of chemicals and salts (e.g., $\mathrm{NaCl}$ ) can also occur through other pathways such as snow scavenging of airborne pollution and the deposition of sea salt aerosol which serves as an additional source to the sea ice system. ${ }^{4,5,15}$ However, in this study, airborne sources were negligible (demonstrated by clean blanks). Hence, chemicals present in our experimental sea ice are shown to have originated from the seawater. The results shown in Table 2 from Freeze-1 also show that only a small fraction (3-9\%) of the total initial mass of chemicals present in the seawater was entrapped within sea ice during its formation, akin to salt (7\%).

3.2. Entrainment of POPs in Sea Ice. A time-series for the concentration of $\mathrm{NaCl}$ and chemicals in seawater throughout the experiment (days 1-11) can be seen in SI Figure S1. During the period of sea ice formation (days 1-4) an increase in sea ice thickness and decrease in seawater volume was accompanied by solute rejection from the sea ice, and an increase in the underlying $\mathrm{NaCl}$ concentration (from around 35 to $39 \mathrm{~g} \mathrm{~L}^{-1}$ ). Given the experimental precision of the measurements made for the organic chemicals seawater $(8-40 \%)$, it was not possible to establish whether they followed a similar trend to the salt. However, the measured concentrations of salt and all chemicals were markedly lower in bulk ice than seawater, as indicated by the Enrichment Factors $\left(\mathrm{EF}_{\mathrm{BI}-\mathrm{SW}}<1\right)$ presented in Table 3. This finding suggests that organic chemicals are rejected from sea ice throughout ice

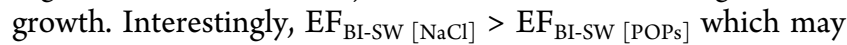
indicate preferential rejection of organic chemicals during seaice growth.
Despite the low chemical concentrations present in bulk ice, results presented in Table 3 show that $\mathrm{EF}_{\mathrm{BR}-\mathrm{SW}}>\mathrm{EF}_{\mathrm{BI}-\mathrm{SW}}(p<$ 0.05 ; student $t$ test), indicating that the chemicals are more strongly associated with the brine fraction and are entrained within the complex network of brine inclusions which extends throughout the ice. ${ }^{24}$ Pucko et al., ${ }^{8}$ quoted the mean depthaveraged salinity of bulk ice to be $11.6 \mathrm{~g} \mathrm{~L}^{-1}$ which gave $\mathrm{EF}_{\mathrm{BI}-\mathrm{SW}}=0.4$ for $\mathrm{NaCl}$. Similarly, values for $\mathrm{EF}_{\mathrm{BI}-\mathrm{SW}}$ were obtained for $\alpha-\mathrm{HCH}$ and $\gamma-\mathrm{HCH}$ at 0.4 and 0.5 , respectively. The resemblance between this calculated index for $\mathrm{NaCl}$ and the two $\mathrm{HCH}$ isomers suggests that the levels of $\mathrm{HCH}$ in FYI are probably governed by processes that function to conservatively distribute brine in sea ice. In our study, $\mathrm{EF}_{\mathrm{BI}-\mathrm{SW}}$ of $\mathrm{NaCl}$ resulted in a value of 0.4 , although there is a larger range $(0.1-0.4)$ between the index for all of the chemicals presented in our study. Natural sea ice is a highly complex medium with marked heterogeneity in physical features over relatively narrow spatial scales (i.e., cms). The chamber ice is markedly younger and thinner than the mid/late-winter Arctic sea ice measured in the field studies above, but the ice formation processes and physical features such as brine channels and frost flowers etc are similar. ${ }^{23}$ Some of the differences between our enrichment factors and previous field studies could be due to different temperature and sea-ice growth regimes. However, the higher brine salinity concentrations observed in the Arctic sea ice could have affected organic chemical occurrence and distribution, and is likely to account for differences between the field studies and the chamber ice of this study.

Brine salinity is set by the appropriate liquidus relationship ${ }^{25}$ and is usually at its respective freezing-point. Changes in the local thermal conditions will cause a corresponding phasechange following this temperature-salinity relationship. Brine salinity measured in Pućko et al., ${ }^{8}$ and in this study was $128 \mathrm{~g}$ $\mathrm{L}^{-1}$ and $58 \mathrm{~g} \mathrm{~L}^{-1}$, respectively. Hence, the brine collected in our study was much less concentrated and this is likely to be attributed to differences in sea ice properties (given the age and thickness of the chamber ice) as well as the brine sampling techniques which limited our ability to obtain enough brine for analysis with a salinity $>58 \mathrm{~g} \mathrm{~L}^{-1}$. These factors most likely contribute to the slightly lower EFs measured in this study compared to those calculated from Arctic sea ice. ${ }^{8,9}$ Furthermore, additional pollution sources such as the transfer of chemicals from the overlying snowpack into sea ice and the 
incorporation of other seawater constituents such as organic matter (dissolved and particulate) may also affect the quantity and distribution of POPs in natural sea ice.

3.3. Distribution of Chemicals within Sea Ice. Figure 1 shows the vertical distribution of salt and chemicals in our
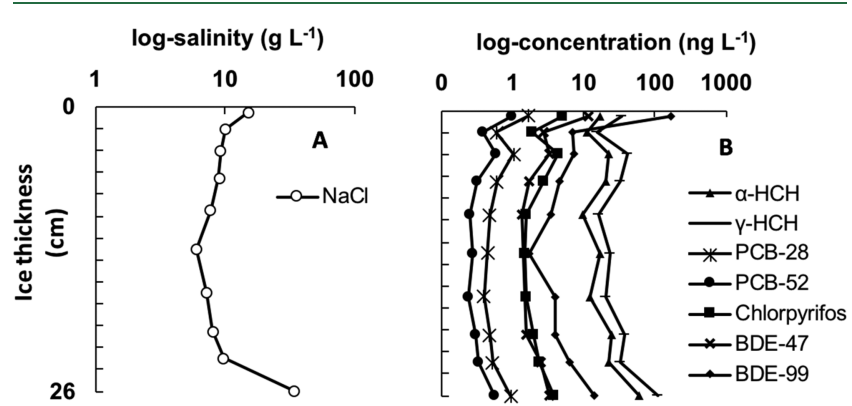

Figure 1. Chemical concentrations in a vertical section of sea ice grown at $-18{ }^{\circ} \mathrm{C}$ to a depth of $26 \mathrm{~cm}$. Zero on the $y$-axis represents the upper most surface of the ice in contact with the chamber atmosphere.

chamber-grown sea ice. Data were plotted on a log-scale to show all chemicals and account for their wide range in concentrations. A "c-shape" profile for bulk salinity (Panel A) is typical for first-year sea ice, whereby elevated concentrations exist at the ice-atmosphere and ice-ocean interfaces. The processes governing the distribution of $\mathrm{NaCl}$ in sea ice have been reviewed by Notz and Worster. ${ }^{14}$ Due to the crystal structure and the close-packing arrangement of water molecules in ice, there is limited inclusion of solutes (e.g., dissolved ions, particulates etc.) within the ice itself, ${ }^{24}$ but are retained within liquid inclusions between the ice lamellae. Due to surface cooling, brine at the surface of sea ice is colder, more saline, and denser than that below, driving convection currents and facilitating the downward movement of salt-rich brine. This process is better known as gravity drainage and is believed to be the predominant mechanism controlling the removal of salts from the bulk sea ice. ${ }^{14}$

We are confident that the $\mathrm{NaCl}$ profile provided in Figure 1 is driven by brine gravity drainage processes. ${ }^{23}$ As the profiles for each organic chemical (Panel B) display a similar shape, we suggest that their distribution in young sea ice is strongly influenced by brine advection during ice growth.

3.4. Accumulation of POPs in Frost Flowers. Frost flowers (FF) are highly saline ice structures that develop on the surface of newly formed sea ice, typically refreezing leads. ${ }^{26}$ The salinity of frost flowers sampled in polar environments have been measured up to $110 \mathrm{~g} \mathrm{~L}^{-1}$ (i.e., $\mathrm{EF}_{\mathrm{FF}-\mathrm{SW}}=3$ ) ${ }^{27}$ and are typically enriched in other sea-salt ions as well. ${ }^{28,29}$ The leading mechanism proposed for this enrichment suggests that freezing water vapor located at the sea ice surface forms an ice skeleton, causing salts and other solutes to be advected from the surface layer through capillary action. ${ }^{28}$ In our study, frost flowers covered around $10 \%$ of the surface area of the ice (Freeze -1) and melted samples measured a salinity of $83 \mathrm{~g}$ $\mathrm{L}^{-1}$, representing a significant enrichment of $\mathrm{NaCl}$ from the upper layer layer $\left(\mathrm{EF}_{\mathrm{FF}-\mathrm{L} 1}=5.0 \pm<0.1\right)$. Results displayed in Table 3 show that $\mathrm{EF}_{\mathrm{FF}-\mathrm{L} 1 \text { [POPs] }}>1$, indicating they too are advected with brine from the surface layer, but to a lesser degree. However, chemical enrichment factors $\left(\mathrm{EF}_{\mathrm{FF}-\mathrm{L} 1}\right)$ for BDE-47 and BDE-99 were $30 \pm 20$ and $50 \pm 31$, respectively, indicating selective fractionation of organic chemicals in frost flowers. Douglas et al. ${ }^{10}$ observed similar enrichments $\left(\mathrm{EF}_{\mathrm{FF}-\mathrm{L} 1}\right.$ $=2-68$ ) for a number of analogous chemicals, including higher-chlorinated-PCBs, in frost flowers sampled on coastal sea ice close to Barrow, Alaska.

The relatively large surface area of frost flowers has been suggested as an important feature that enhances the atmospheric scavenging of airborne chemicals. ${ }^{10}$ However, atmospheric scavenging is unlikely to be significant in our experiments because the blanks revealed negligible levels of the chemicals in the chamber air (SI Table S3). A possible mechanism for observing enrichment in frost flowers involves evaporation of chemicals from the relatively warmer surface ice layer, and subsequent condensation to the colder frost flowers. ${ }^{10}$ However, we propose that organic solutes may be advected from the ice at different rates and related to factors controlled by their individual physicochemical properties. The high enrichment observed for some of these chemicals suggests that frost flowers may play an important role in the iceatmosphere exchange of POPs in polar marine environments.

3.5. Simulated Chemical Behavior in Sea Ice. The initial $\mathrm{NaCl}$ and chemical concentrations measured in the seawater were used as input parameters for the brine dynamics model. The model predicts the convection of brine, driven by gravity drainage, assuming that (i) the chemicals are perfectly dissolved and are advected with the moving brine; (ii) the chemicals are well-mixed in the underlying seawater. Figure 2 shows an example of a comparison between the predicted and measured chemical distribution of $\mathrm{NaCl}$ (Panel A), $\alpha-\mathrm{HCH}$ (Panel B) and BDE-47 (Panel C) (see SI Figures S3 and S4 for other chemical profiles), normalized by ice thickness. The model produced a predictable "c-shape" concentration profile for $\mathrm{NaCl}$ and organic chemicals, where concentrations were generally highest at the upper and lower sea ice interface.

Although a qualitative comparison between the measured and modeled chemical profiles in the sea ice was reasonable, the model tended to overestimate the concentrations of the

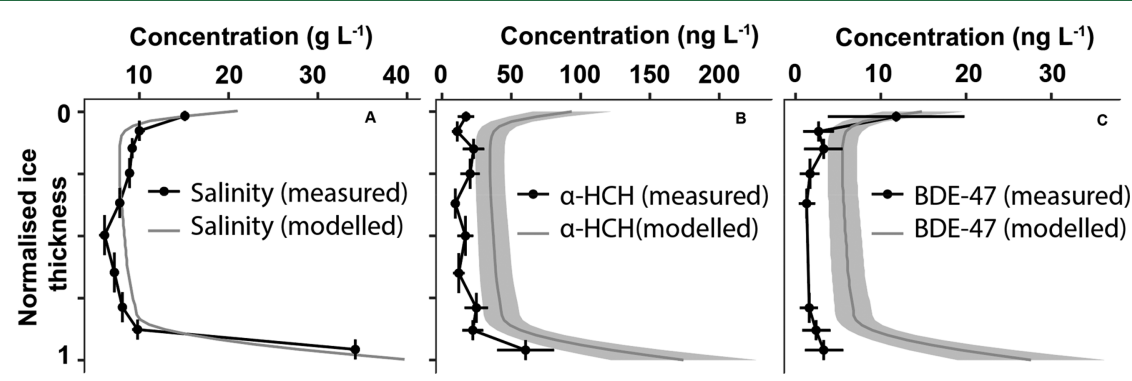

Figure 2. Modeled and measured bulk concentration profile for salinity, $\alpha-\mathrm{HCH}$ and BDE-47 in sea ice grown at $-18^{\circ} \mathrm{C}$ to a depth of $26 \mathrm{~cm}$. Vertical bars indicate layer thickness. Horizontal bars represent \pm 2 SD for measured and modeled data (gray shade) 
organic chemicals. A ratio of the modeled and measured bulk ice concentrations (integrated vertically over all the sea ice layers) showed a ratio for $\mathrm{NaCl}$ of around 1, whereas a ratio of 9 was observed for BDE-47 (see SI Table S6 for other chemicals). The comparison suggests that low-polarity organic compounds may not be transported conservatively with respect to salt. Rather, additional factors other than gravity drainage may also play a role in the degree of chemical incorporation during sea ice growth.

The extreme environment (i.e., low temperatures and high brine salinity) in sea ice causes large uncertainties regarding the physical-chemical properties of organic solutes in brine inclusions. We derived simple salinity-temperature dependent relationships for each chemical to estimate whether the aqueous solubility was exceeded at the minimum recorded temperature and highest modeled brine salinity within the sea ice (listed in Table 1). Our basic approach indicated that the aqueous solubility was not exceeded for each chemical at these conditions. While we can not state conclusively that this factor did not affect the distribution of chemicals in our experiments, our results suggest that another process(es) currently not described by the physics incorporated within the brine dynamics model may also be at play. Given the dynamic nature of our artificial sea ice, chemical solutes are unlikely to attain equilibrium between the seawater, ice surfaces and ice brine compartments. As sea ice grows thicker (late season Arctic sea ice may be several meters thick), the rate of ice growth generally decreases, allowing more time for exchange of organic chemicals between these compartments and affecting their accumulation in sea ice. We therefore propose that thermodynamic factors such as the partitioning of low polarity organic contaminants between these different ice compartments $^{30}$ (processes which do not feature in the model) may account for the descrepancy between the observed and modeled values.

3.6. Brine Composition and Chemical Dynamics. The thermodynamic state controls the fluid dynamics of sea ice and plays a crucial role in the biogeochemical cycling of sea ice constituents. ${ }^{8,21,31,32}$ As the brine volume of sea ice approaches around $5 \%$, it is generally accepted that sea ice becomes sufficiently permeable to permit brine to move freely. ${ }^{33}$ However, the melting of natural sea ice and hence its desalination during seasonal thaw is a complex process that is governed by the properties of the sea ice and the thermal regime (i.e., basal melt or surface melt). We conducted a slowmelt experiment (see Section 2.4.) to investigate the association of organic chemicals with different meltwater fractions of varying $\mathrm{NaCl}$ concentrations. This enabled us to observe the composition of brine and therefore infer the temporal behavior of organic contaminants in sea ice during the transition from FYI to older MYI.

The experiment resulted in brine-rich meltwater being released first (e.g., $\mathrm{NaCl} ; \mathrm{MW}_{\mathrm{F} 1}=58 \mathrm{~g} \mathrm{~L}^{-1}$ ), followed by a supply of fresher meltwater due to the melting of the ice-matrix itself (e.g., $\mathrm{NaCl} ; \mathrm{MW}_{\mathrm{F} 4}=1.9 \mathrm{~g} \mathrm{~L}^{-1}$ ), indicating that brine release is governed by thermodynamically controlled phasechanges within the sea ice pores. SI Figure S2 shows that the level of chemical enrichment in meltwater (i.e., $\mathrm{EF}_{\mathrm{MW}-\mathrm{SW}}$ ) was positively correlated $\left(n=48, r^{2}=0.507, p<0.01\right)$ with the concentration of $\mathrm{NaCl}$ in the sea ice meltwater. Therefore, saltier brine can be expected to contain higher concentrations of chemicals. Our results are consistent with field studies investigating inorganic ${ }^{21,31}$ and organic ${ }^{8,9}$ chemical behavior in sea ice.

Despite earlier meltwater fractions showing a higher degree of chemical enrichment, the volumes of meltwater that were collected varied from 0.2 to $2.4 \mathrm{~L}$ (see SI Table S7). To further investigate the dynamics of chemicals during melt, the percentage mass of chemical in each meltwater fraction was calculated (see SI Table S8) and shown in Figure 3. The

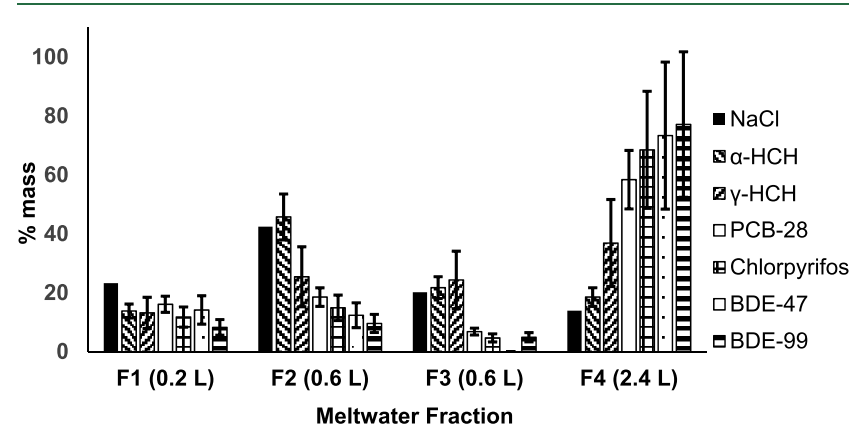

Figure 3. Percentage mass of individual chemicals in the sequential meltwater fractions. Bracketed values are the actual volumes for each meltwater fraction. PCB-52 was < MDL in several fractions and so was not included in this plot. Error bars calculated from RSD.

results show that the highest mass of the most hydrophobic chemicals (PCB-28, chlorpyrifos, BDE-47, BDE-99) was present in the final meltwater fraction $\left(\mathrm{MW}_{\mathrm{F} 4}\right)$, unlike $\mathrm{NaCl}$ which has the lowest mass in $\mathrm{MW}_{\mathrm{F} 4}$. The results indicate that organic chemicals can be retained within the bulk sea ice even after the brine has drained and implies that more hydrophobic chemicals are preferentially retained within the sea ice.

The three initial meltwater fractions $\left(\mathrm{MW}_{\mathrm{F} 1-\mathrm{F} 3}\right)$ show that chemical mass loss from the ice is lower than salt, but highest for the more water-soluble chemicals (i.e., around 75\% of $\alpha$ $\mathrm{HCH}$ and $\gamma-\mathrm{HCH}$ is lost in $\mathrm{F} 1-\mathrm{F} 3$, compared to only around $20 \%$ of $\mathrm{BDE}-99)$. The final melt fraction $\left(\mathrm{MW}_{\mathrm{F} 4}\right)$ contained $>50 \%$ of the mass of (in increasing order) PCB-28, chlorpyrifos, BDE-47, and BDE-99, initially present in the ice prior to the onset of melt. The results suggest that chemicals are released at variable rates, possibly due to thermodynamic factors associated with the aqueous solubility and the rate of dissolution, ${ }^{34}$ which may affect the phase distribution and rate of transfer between the solid fresh ice matrix to the mobile liquid brine solution. This observation is comparable to studies performed in environmental and laboratory snow, whereby soluble ions are generally released in initial meltwater fractions (i.e., "type I elution" see refs 35 and 36), wheareas very hydrophobic organic compounds (possibly associated with particles), are retained in the snow until final meltwater elution associated with complete melting (i.e., "type II elution").

Our results show that brine dynamics play an important role in the distribution of persistent chemicals in young sea ice, supporting our hypothesis that chemical uptake and distribution is strongly influenced by the formation of brine during sea ice growth. However, chemical specific processes may remove these chemicals from the dissolved phase, decoupling them from the $\mathrm{NaCl}$ within the sea ice system. Support for this assertion comes from our melting experiments where chemicals were released from the sea ice at varying rates. The most hydrophobic chemicals were preferentially retained within the sea ice relative to the more water-soluble chemicals, and to $\mathrm{NaCl}$. Physical-chemical processes such as adsorption 
to brine inclusion walls or precipitation within brine inclusions are promising explanations for this behavior. Our results have several important implications for the biogeochemical cycling of persistent organic pollutants in natural sea ice, by (i) altering the input rate of different contaminants to surface waters from melting sea ice; (ii) affecting the level and retention rates of chemical contaminants in FYI and subsequent MYI; and (iii) controlling the spatial and temporal exposure of chemicals to ice-associated biota.

\section{ASSOCIATED CONTENT}

\section{S Supporting Information}

The Supporting Information is available free of charge on the ACS Publications website at DOI: 10.1021/acs.est.9b00967.

Tables S1-S7 show chemical data along with associated eqs $\mathrm{S} 1-\mathrm{S} 5$ and Figures S1-S4 (PDF)

\section{AUTHOR INFORMATION}

\section{Corresponding Author}

*E-mail: c.halsall@lancaster.ac.uk. ORCID $\odot$

Jack Garnett: 0000-0001-9347-3808

Notes

The authors declare no competing financial interest.

\section{ACKNOWLEDGMENTS}

J.G.'s PhD (NE/L002604/1) was funded through NERC's ENVISION Doctoral Training Centre. This work resulted from the EISPAC project (NE/R012857/1), part of the Changing Arctic Ocean programme, jointly funded by the UKRI Natural Environment Research Council (NERC) and the German Federal Ministry of Education and Research (BMBF). We are grateful to the British Antarctic Survey for providing funding (British Antarctic Survey Collaboration Voucher) to cover the running costs of the RvG-ASIC facility for the duration of the experimental period. This project/work has received funding from the European Union's Horizon 2020 research and innovation programme through the EUROCHAMP-2020 Infrastructure Activity under grant agreement No. 730997. We thank Professor Finlo Cottier and two other anonymous reviewers.

\section{REFERENCES}

(1) UNEP. Global Report 2003-Regionally Based Assessment of Persistent Toxic Substances; Geneva, Switzerland, 2003. https://www. researchgate.net/profile/Hindrik_Bouwman/publication/ 292286858_Regionally_based_assessment_of_persistent_toxic substances_Global_reprt/links/56ac8fb408ae19a38513 e2 e7 Regionally-based-assessment-of-persistent-toxic-substances-Globalreprt.pdf.

(2) de Wit, C. A.; Muir, D. Levels and trends of new contaminants, temporal trends of legacy contaminants and effects of contaminants in the Arctic: Preface. Sci. Total Environ. 2010, 408 (15), 2852-2853.

(3) AMAP. AMAP Assessment 2016: Chemicals of Emerging Arctic Concern; Oslo, Norway, 2017; p 353. https://www.amap.no/ documents/doc/AMAP-Assessment-2016-Chemicals-of-EmergingArctic-Concern/1624.

(4) Cai, M.; Yang, H.; Xie, Z.; Zhao, Z.; Wang, F.; Lu, Z.; Sturm, R.; Ebinghaus, R. Per- and polyfluoroalkyl substances in snow, lake, surface runoff water and coastal seawater in Fildes Peninsula, King George Island, Antarctica. J. Hazard. Mater. 2012, 209-210, 335342 .
(5) Pućko, M.; Stern, G. A.; Macdonald, R. W.; Rosenberg, B.; Barber, D. G., The influence of the atmosphere-snow-ice-ocean interactions on the levels of hexachlorocyclohexanes in the Arctic cryosphere. J. Geophys. Res., Oceans 2011, 116 (C2), n/a-n/a; DOI: 10.1029/2010JC006614.

(6) Pućko, M.; Stern, G. A.; Macdonald, R. W.; Jantunen, L. M.; Bidleman, T. F.; Wong, F.; Barber, D. G.; Rysgaard, S. The delivery of organic contaminants to the Arctic food web: Why sea ice matters. Sci. Total Environ. 2015, 506-507, 444-452.

(7) Gustafsson, Ö.; Andersson, P.; Axelman, J.; Bucheli, T. D.; Kömp, P.; McLachlan, M. S.; Sobek, A.; Thörngren, J. O. Observations of the PCB distribution within and in-between ice, snow, ice-rafted debris, ice-interstitial water, and seawater in the Barents Sea marginal ice zone and the North Pole area. Sci. Total Environ. 2005, 342 (1), 261-279.

(8) Pućko, M.; Stern, G.; Macdonald, R. W.; Barber, D. G. alphaand gamma-Hexachlorocyclohexane Measurements in the Brine Fraction of Sea Ice in the Canadian High Arctic Using a SumpHole Technique. Environ. Sci. Technol. 2010, 44 (24), 9258-9264.

(9) Pućko, M.; Stern, G. A.; Barber, D. G.; Macdonald, R. W.; Rosenberg, B. The international polar year (IPY) circumpolar flaw lead (CFL) system study: The importance of brine processes for $\alpha$ and $\gamma$-hexachlorocyclohexane $(\mathrm{HCH})$ accumulation or rejection in sea ice. Atmos.-Ocean 2010, 48 (4), 244-262.

(10) Douglas, T. A.; Domine, F.; Barret, M.; Anastasio, C.; Beine, H. J.; Bottenheim, J.; Grannas, A.; Houdier, S.; Netcheva, S.; Rowland, G.; Staebler, R.; Steffen, A., Frost flowers growing in the Arctic oceanatmosphere-sea ice-snow interface: 1. Chemical composition. J. Geophys. Res., Atmos. 2012, 117 (D14); DOI: 10.1029/ 2011JD016460.

(11) Vaughan, D. G.; C, J. C.; Allison, I.; Carrasco, J.; Kaser, G.; Kwok, R.; Mote, P.; Murray, T.; Paul, F.; Ren, J.; Rignot, E.; Solomina, O.; Steffen, K.; Zhang, T. Observations: Cryosphere. In Climate Change 2013: The Physical Science Basis. Contribution of Working Group I to the Fifth Assessment Report of the Intergovernmental Panel on Climate Change; Cambridge University: Cambridge, U.K., 2013.

(12) NSIDC All About Sea Ice: Arctic vs. Antarctic. https://nsidc. org/cryosphere/seaice/characteristics/difference.html.

(13) Perovich, D.; M, W.; Tschudi, M.; Farrel, S.; Hendricks, S.; Gerland, S.; Haas, C.; Krumpen, T.; Polashenski, C.; Ricker, R.; Webster, M. Sea Ice. In: Arctic Report Card 2015. https://www. arctic.noaa.gov/report-card.

(14) Notz, D.; Worster, M. G., Desalination processes of sea ice revisited. J. Geophys. Research:., Oceans 2009, 114 (C5); DOI: $10.1029 / 2008$ JC004885.

(15) Pućko, M.; Stern, G. A.; Barber, D. G.; Macdonald, R. W.; Warner, K. A.; Fuchs, C. Mechanisms and implications of $\alpha-\mathrm{HCH}$ enrichment in melt pond water on Arctic sea ice. Environ. Sci. Technol. 2012, 46 (21), 11862.

(16) Pućko, M.; Stern, G. A.; Burt, A. E.; Jantunen, L. M.; Bidleman, T. F.; Macdonald, R. W.; Barber, D. G.; Geilfus, N.-X.; Rysgaard, S. Current use pesticide and legacy organochlorine pesticide dynamics at the ocean-sea ice-atmosphere interface in resolute passage, Canadian Arctic, during winter-summer transition. Sci. Total Environ. 2017, 580, $1460-1469$.

(17) Rees Jones, D. W.; Worster, M. G. A physically based parameterization of gravity drainage for sea-ice modeling. Journal of Geophysical Research: Oceans 2014, 119 (9), 5599-5621.

(18) Cottier, F.; Eicken, H.; Wadhams, P. Linkages between salinity and brine channel distribution in young sea ice. Journal of Geophysical Research: Oceans 1999, 104 (C7), 15859-15871.

(19) Fripiat, F.; Cardinal, D.; Tison, J. L.; Worby, A.; André, L., Diatom-induced silicon isotopic fractionation in Antarctic sea ice. J. Geophys. Res., Biogeosci. 2007, 112 (G2); DOI: 10.1029/ 2006JG000244.

(20) Nomura, D.; Takatsuka, T.; Ishikawa, M.; Kawamura, T.; Shirasawa, K.; Yoshikawa-Inoue, H. Transport of chemical components in sea ice and under-ice water during melting in the seasonally 
ice-covered Saroma-ko Lagoon, Hokkaido, Japan. Estuarine, Coastal Shelf Sci. 2009, 81 (2), 201-209.

(21) Fripiat, F.; Sigman, D. M.; Fawcett, S. E.; Rafter, P. A.; Weigand, M. A.; Tison, J. L. New insights into sea ice nitrogen biogeochemical dynamics from the nitrogen isotopes. Global Biogeochemical Cycles 2014, 28 (2), 115-130.

(22) Miller, L. A.; F, F.; Brent, G. T. Else; Bowman, J S; Brown, K A; Collins, E R; Ewert, M.; Fransson, A.; Gosselin, M.; Lannuzel, D.; Meiners, K M; Michel, C.; Nishioka, J.; Nomura, D.; Papadimitriou, S.; Russell, L M; Sørensen, L L; Thomas, D N; Tison, J-L; A. van Leeuwe, M.; Vancoppenolle, M.; Wolff, E W; Zhou, J., Methods for biogeochemical studies of sea ice: The state of the art, caveats, and recommendations. Elementa: Science of the Anthropocene. 2015, 3; DOI: 10.12952/journal.elementa.000038.

(23) Thomas, M. Brine and pressure dynamics in growing sea ice: first results from the Roland von Glasow air-sea-ice chamber. Ph.D, University of East Anglia: Norwich, U.K., 2019.

(24) Petrich, C.; E., Hajo, Overview of sea ice growth and properties. In Sea ice, 3rd ed.; John Wiley \& Sons: Chichester, U.K., 2017; pp 141.

(25) Assur, A., Composition of sea ice and its tensile strength. In Arctic Sea Ice; Easton, M., Ed.; National Research Council: Washington: Easton, MD, 1958; pp 106-138.

(26) Perovich, D. K.; Richter-Menge, J. A. Surface characteristics of lead ice. J. Geophys. Res. 1994, 99 (C8), 16341-16350.

(27) Barber, D. G.; E, J. K.; Pućko, M.; Rysgaard, S.; Deming, J. W.; Bowman, J. S.; Papakyriakou, T.; Galley, R. J.; Sogaard, D. H. Frost flowers on young Arctic sea ice: The climatic, chemical, and microbial significance of an emerging ice type. Journal Of Geophysical ResearchAtmospheres 2014, 119 (20), 11593-11612.

(28) Alvarez-Aviles, L.; Simpson, W. R.; Douglas, T. A.; Sturm, M.; Perovich, D.; Domine, F., Frost flower chemical composition during growth and its implications for aerosol production and bromine activation. J. Geophys. Res., Atmos. 2008, 113 (D21); DOI: 10.1029/ 2008JD010277.

(29) Rankin, A. M.; Wolff, E. W.; Martin, S. Frost flowers: Implications for tropospheric chemistry and ice core interpretation. Journal of Geophysical Research: Atmospheres 2002, 107 (D23), AAC 4-1-AAC 4-15.

(30) Schwarzenbach, R. P. G., Phillip, M; Imboden, Dieter, M, Sorption of Nonionic organic compounds to Inorganic Surfaces in Water. In Environmental Organic Chemistry; John Wiley \& Sons: Hoboken, NJ, 2003; pp 389-417.

(31) Lannuzel, D.; Bowie, A. R.; van Der Merwe, P. C.; Townsend, A. T.; Schoemann, V. Distribution of dissolved and particulate metals in Antarctic sea ice. Mar. Chem. 2011, 124 (1), 134-146.

(32) Zhou, J.; Delille, B.; Kaartokallio, H.; Kattner, G.; Kuosa, H.; Tison, J. L.; Autio, R.; Dieckmann, G. S.; Evers, K. U.; Jørgensen, L.; Kennedy, H.; Kotovitch, M.; Luhtanen, A. M.; Stedmon, C. A.; Thomas, D. N. Physical and bacterial controls on inorganic nutrients and dissolved organic carbon during a sea ice growth and decay experiment. Mar. Chem. 2014, 166 (C), 59-69.

(33) Golden; Ackley; Lytle. The percolation phase transition in sea Ice. Science (Washington, DC, U. S.) 1998, 282 (5397), 2238.

(34) Schwarzenbach, R. P.; G, P. M.; Imboden, D. M. Molecular interpretation of the Excess Free Energy of Organic Compounds in Aqueous Solutions. In Environmental Organic Chemistry; John Wiley \& Sons: Hoboken, NJ, 2003; pp 142-180.

(35) Meyer, T.; Lei, Y.; Muradi, I.; Wania, F. Organic Contaminant Release from Melting Snow. 2. Influence of Snow Pack and Melt Characteristics. Environ. Sci. Technol. 2009, 43 (3), 663.

(36) Meyer, T.; Lei, Y.; Muradi, I.; Wania, F. Organic Contaminant Release from Melting Snow. 1. Influence of Chemical Partitioning. Environ. Sci. Technol. 2009, 43 (3), 657. 